\title{
İnfluenza A ya Bağıı Postenfeksiyöz Serebellar Ataksi ve Hepatit: Olgu Sunumu
}

\author{
Postinfectious Cerebellar Ataxia and Hepatitis due to Influenza A: \\ A Case Report
}

\author{
Latife GÜDER ${ }^{1}$, Melike ARSLAN², Necati BALAMTEKIN
}

Yazışma Adresi

Correspondence Address

\section{Melike ARSLAN}

Gülhane Tip Fakültesi Çocuk

Sağlığı ve Hastalıkları AD, Çocuk Gastroenterolojisi BD, Ankara,

Türkiye

E-posta: melikearslan190@gmail. com

Geliş tarihi \Received : 14.04 .2020 Kabul tarihi \ Accepted : 04.06.2020 Elektronik yayn tarihi $\quad: 12.07 .2021$ Online published

Bu makaleye yapilacak atıf: Gite this article as:

Güder L, Arslan M, Balamtekin N. Influenza A ya bağlı postenfeksiyöz serebellar ataksi ve hepatit: Olgu sunumu. Akd Tip D 2021; 7(2):319-322

Latife GÜDER

ORCID ID: 0000-0003-4565-3665

Melike ARSLAN

ORCID ID: 0000-0002-0107-4699

Necati BALAMTEKIN

ORCID ID: 0000-0001-8665-5611
'Gülhane Tip Fakültesi Çocuk Sağlığı ve Hastalıkları AD, Ankara, Türkiye

${ }^{2}$ Gülhane Tıp Fakültesi Çocuk Sağlığı ve Hastalıkları AD, Çıcuk Gastroenterolojisi BD, Ankara, Türkiye

\section{ÖZ}

İnfluenza, sağlıklı çocuklarda genellikle kendi kendini sınırlayan bir enfeksiyon olarak karşımıza çıkmaktadır; ancak birçok çocuk hastada komplikasyonlar görülür. İnfluenza virüsleri, solunum sekresyonları ile temas (hapşırma, öksürme, konuşma, dokunma) veya kontamine nesneler yoluyla insandan insana bulaşır. Genellikle; hava, damlacık ve temas yolu ile insandan insana bulaşır. Titreme ile yükselen ateş, baş ağrısı, miyalji, halsizlik, iştahsızlık, fotofobi ve balgamsız öksürük sık saptanan semptomlardır. İnfluenza enfeksiyonuna bağlı olarak miyozit, febril konvülsiyon, Reye sendromu, aseptik menenjit, akut serebeller ataksi, transvers myelit, Guillain-Barré sendromu, akut dissemine ensefalomyelit, miyokardit, perikardit ve hepatit gibi komplikasyonlar gelişebilmektedir. Bu makalede influenza A ya bağlı gelişen post enfeksiyöz serebellit ve hepatit tanısı alan bir çocuk hasta sunulmaktadir.

Anahtar Sözcükler: İnfluenza A, Post enfeksiyöz serebellit, Ataksi, Hepatit

\begin{abstract}
Influenza often appears as a self-limiting infection in healthy children; but in many children complications appear. Influenza viruses are spread from person to person, through contact with respiratory secretions (through sneezing, coughing, talking, touching) or by contaminated objects. Generally; transmitted from person to person by air, droplet and contact. Fever rising with chills, headache, myalgia, weakness, loss of appetite, photophobia and cough without sputumare common symptoms. Depending on the influenza infection, complications such as myositis, febrile convulsion, Reye's syndrome, aseptic meningitis, acute cerebellar ataxia, transverse myelitis, Guillain-Barré syndrome, acute disseminated encephalomyelitis, myocarditis, pericarditis and hepatitis may develop. In this article, a pediatric patient diagnosed with post-infectious cerebellitis and hepatitis due to influenza A is presented.
\end{abstract}

Keywords: Influenza A, Post infectious cerebellitis, Ataxia, Hepatitis

\section{GiRiş}

İnfluenza enfeksiyonunun etkeni, influenza A, B ve $\mathrm{C}$ influenza virüsleridir. İnfluenza virüsü, Orthomyxoviridae ailesinden tek zincirli bir ribonükleik asit (RNA) virüsü olup, Türkiye gibi ılıman iklim kuşağında bulunan ülkelerde kış mevsiminde salgınlar meydana getirir. Influenza, akut bir solunum yolu enfeksiyonudur; alt veya üst solunum sistemini etkileyebilir. İnfluenza $\mathrm{C}$ virüsü, daha çok hafif üst solunum yolu hastalı̆̆ına neden olan, nadir bir etkendir. İnfluenza A ve B ise salginlardan sorumlu olan virüs tipleri olup, hemaglütinin ve nöraminidaz adı verilen yüzey proteinlerine göre, serotiplere ayrılır (1). 
Mevsimsel influenza seyri, hem konağın hem de virüsün özelliklerine bağlı olarak asemptomatik bir enfeksiyondan fulminan bir hastalığa kadar değişir. Semptomlar 1-2 günlük bir kuluçka döneminden sonra aniden ortaya çıkar ve ateş, titreme, baş ağrısı, kas ağrısı, halsizlik ve iştahsızlık gibi çeşitli sistemik özelliklerle ve öksürük, burun akıntısı, boğaz ağrısı gibi solunum yolu semptomlarıla karakterizedir (2). Fotofobi, konjonktivit, lakrimasyon ve göz hareketleriyle ağrıyı içeren oküler semptomlar da bulunabilir. İnfluenza enfeksiyonu bronşiolit ve krup ile ilişkilidir. Enfeksiyon astım, kronik obstrüktif akciğer hastalığı ve kronik bronşit gibi altta yatan kronik akciğer hastalığı olanlarda hastalığın alevlenmesine yol açabilir. Pulmoner komplikasyonlara ek olarak, influenza enfeksiyonunda kardiak, nörolojik komplikasyonlar, kas-iskelet sistemi ve karaciğger tutulumu görülebilir (2).

$\mathrm{Bu}$ makalede, serebellar ataksi ve hipertransaminazemi ile araştırılırken, İnfluenza A virüsüne bağlı postenfeksiyöz serebellit ve hepatit komplikasyonu geliştirdiği saptanan altı yaşında bir çocuk hasta sunulmuştur.

\section{OLGU SUNUMU}

Altı yaş sekiz aylık erkek hasta, iki gündür devam eden $39^{\circ} \mathrm{C}$ ateş, burun akıntısı, hafif öksürük, iştahsızlık, karın ağrısı, denge bozukluğu ve konuşma bozukluğu nedeniyle çocuk polikliniğimize getirildi. Hastanın, aralarında akrabalık bulunmayan 34 yaşında sağ ve sağlıklı anne ile 37 yaşında sağ ve sağlıklı babanın yaşayan ikinci çocukları olduğu öğrenildi. Fizik muayenesinde vücut ağırlığı 22 kg (25-50 persentil), boy: $119 \mathrm{~cm}$ (25-50 persentil) idi. Orofarenks hiperemik görünümde, postnazal seropürülan akıntı mevcuttu. Nörolojik muayenesinde ataksik yürüyüş ve dizartrisi mevcuttu ve Romberg testi pozitifti. Nistagmus, dismetri, tremor ve disdiadokokinezi yoktu. Diğer sistem muayeneleri normaldi. Laboratuar incelemelerinde, hemoglobin: 11,5 g/dL, beyaz küre: $7.600 / \mathrm{mm} 3$, trombosit: $90.000 / \mathrm{mm} 3$ CRP: $48.5 \mathrm{mg} / \mathrm{L}$ idi. INR: 1.4, rutin biyokimyasal tetkiklerinde, üre: $55 \mathrm{mg} / \mathrm{dL}$, kreatinin: $0.84 \mathrm{mg} / \mathrm{dL}$, AST: 3582 IU/L, ALT: 1119 IU/L, GGT: 79 IU/L, total bilirubin: $1,4 \mathrm{mg} / \mathrm{dL}$, direkt bilirubin: $0,79 \mathrm{mg} / \mathrm{dL}$, total protein: 6.65g/dL, albümin: 4,32 g/dL, sodyum: $137 \mathrm{mmol} / \mathrm{L}$, potasyum: 4,43 $\mathrm{mmol} / \mathrm{L}$, laktat $13,5 \mathrm{mg} / \mathrm{dL}$, amonyak $144,9 \mu \mathrm{g} / \mathrm{dL}$, seruloplazmin $27.3 \mathrm{mg} / \mathrm{dL}, 24$ saatlik idrarda bakır 34,2 mg/gün olarak ölçüldü. EBV, CMV, parvo virüs, Hepatit A, Hepatit B, Hepatit C ve HIV serolojisi negatifti. Alfa-fetoprotein, alfa-1 antitripsin, anti karaciğer-böbrek mikrozomal antikor (LKM), antinükleer antikor (ANA), Anti-dsDNA, antimitokondiryal antikor (AMA), anti düz kas antikorları (ASMA) negatif saptandı. İnfluenza hızlı antijen testinde influenza A pozitif saptandı. Etiyolojiye yönelik yapılan radyolojik çalışmalardan abdominal ultrasonografi normal, beyin MR ve Difüzyon MR da anatomik yapilar normal idi. Serebral hemisferlerin gri ve beyaz cevher sinyal dağılımı homojen ve normal idi. Difüzyon ağırlıklı serilerde difüzyon kısıtlaması saptanmadı (Resim 1-2). Hastaya, fizik muayene ve laboratuvar incelemeleri sonucunda İnfluenza A ya bağlı postenfeksiyöz serebellar ataksi ve hepatit tanısı konularak oseltamivir $2 \times 45 \mathrm{mg}$ ve intravenöz hidrasyon desteği başlandı. Hastanın tedaviye klinik ve laboratuvar yanıtı çok çabuk görüldü; tedavinin üçüncü gününden sonra vücut isısı normale geriledi ve üst solunum yolu enfeksiyonu bulguları hafifledi, nörolojik muayenede ataksisi kayboldu ve Romberg bulgusunun negatif olduğu saptandı. Yatışının üçüncü gününde üre: 13 mg/dl, kreatinin: 0.48 mg/dl , AST: 238 IU/L, ALT: 273

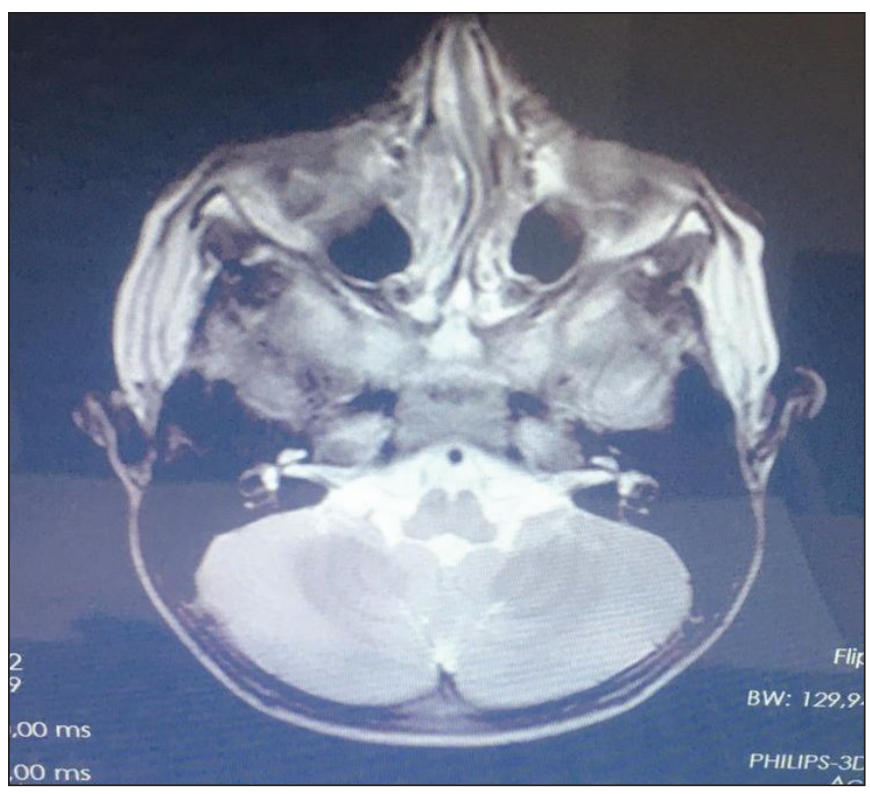

Şekil 1: Normal kranial MR (T1 sekans).

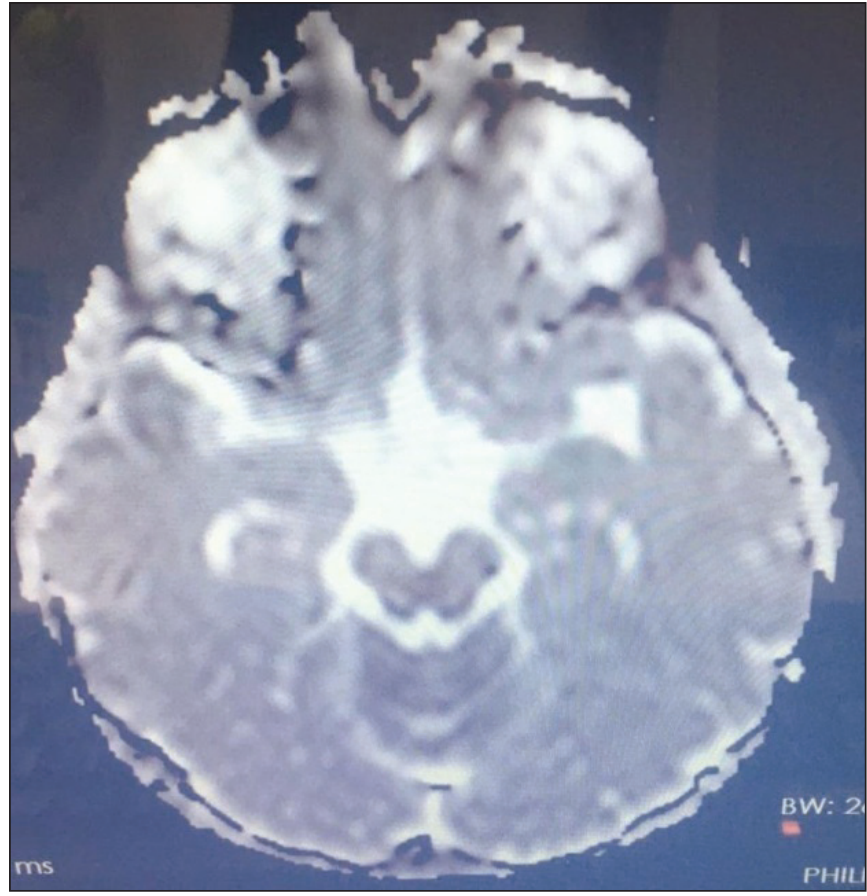

Şekil 2: Normal diffüzyon MR. 
IU/L, GGT: 59 IU/L, total bilirubin: $0,5 \mathrm{mg} / \mathrm{dL}$, direkt bilirubin: $0,07 \mathrm{mg} / \mathrm{dL}$, total protein: $5,65 \mathrm{~g} / \mathrm{dL}$, albümin: 3,57 g/dL, INR: 0.96 olarak ölçüldü. Hasta Oseltamivir tedavisinin 5 güne tamamlanması ve poliklinik kontrolü önerilerek yatışının dördüncü gününde taburcu edildi.

\section{TARTIŞMA}

Çoğu çocuk için influenza, yaklaşık bir haftalık bir hastalıktan sonra semptomların çözülmesi ile kendi kendini sınırlayan bir enfeksiyon olmasına rağmen, birçok pediatrik hasta komplikasyon yaşar. Hem daha önce sağllklı hem de kronik olarak hastalığı olan çocuklar potansiyel olarak akut otitis media (AOM) gibi daha küçük komplikasyonlardan, solunum yetmezliği ve ölüm gibi önemli hastalıklara kadar komplikasyonlara açıktır (3). Sekonder bakteriyel enfeksiyonlar sıklıkla görülür ve çoğunlukla Streptococcus pneumoniae ve Staphylococcus aureus'a bağlıdır. Pnömoni influenzanın önemli bir komplikasyonudur ve hastaneye yatma, solunum yetmezliği ve ölüme yol açabilir (4). İnfluenzaya sekonder solunum dişı komplikasyonlar da ortaya çıkar. Akut miyozit, miyoperikardit te influenza virüsünün kas tutulumuna bağlı gelişebilir. Miyozitli hastalar en çok kas ağrısı ve hassasiyet ile başvururlar (4).

İnfluenzanın nörolojik komplikasyonları nadir olmasına rağmen çocuklarda yetişkinlerden daha sı görülür ve febril konvülsiyon, transvers miyelit, ensefalopati, aseptik menenjit, akut serebellar ataksi ve Guillain-Barre' sendromunu (GBS) içerir (4). Reye sendromu, karaciğger fonksiyon anormallikleri ve yüksek serum amonyak konsantrasyonları ile ilişkili beyin omurilik sıvısı analizinde inflamasyon kanıtı olmadan görülen akut ensefalopati ile karakterizedir. Bu sendrom çoğunlukla aspirin alan çocuklarda meydana gelir ve günümüzde çocuklarda aspirin kullanımı önemli ölçüde azaldığı için çok nadir görülür (2). Bizim hastamızda aspirin kullanım öyküsü olmadığı, serum amonyak düzeyleri normal olduğu ve ensefalopati kliniği olmadığı için Reye sendromu düşünülmedi.

Karaciğer transaminaz düzeylerinin yükselmesi, sistemik enfeksiyonlar sırasında sık görülen bir bulgudur, ancak influenzada karaciğer hasarı insidansı belirlenmemiştir ve karaciğer tutulumunun patogenezi hala iyi anlaşılmamıştır. Hayvan modellerinde karaciğer hasarı gösterilmiştir ve hepatoselüler hasar üretmek için virüs replikasyonunun gerekli olmadığı ortaya koyulmuştur. Sitokinlerin üretimi (örn, TNF-alfa, IL-6, IL-8, IL-10 ve interferon alfa, interferon beta ve interferon gama) hepatosit yaralanmasına yol açan hepatik oksidatif stresten sorumludur (5). Bizim hastamızda da influenza enfeksiyonunun nadir komplikasyonları olan akut serebellar ataksi ve hepatit bir arada görülmüsstür.

Serebellar ataksi, ana semptom olarak ataksi ile birlikte geniş bir nörolojik bozukluk spektrumunu içeren ve klinik olarak denge ve koordinasyon kaybını ifade eden bir terimdir. Ataksi, sinir sisteminin çeşitli bölümlerindeki (ör. serebellum, beyin sapı, omurilik ve periferik sinirler) bozukluklardan kaynaklanabilir. Akut serebellar ataksiler (ACA) çocukluk çağında daha sık görülür ve sıklıkla enfeksiyon sonrası bir bozukluk olarak ortaya çıkar. Enfeksiyon hastalıklarına sekonder akut serebellar ataksiler en sık posterior fossayı içerir ve pediyatrik popülasyonda, akut ataksinin en sık nedeni serebellittir (6).

Akut postenfeksiyöz serebellit, çocuklarda ve genç yetişkinlerde daha yaygındır. Başlangıçta normal veya anormal beyin manyetik rezonans görüntüleme (MRG) bulgularının görülebildiği serebellar bir sendromdur. Serebellite yol açtı̆̆ı daha önce bildirilen enfeksiyonlar şunlardır: EpsteinBarr virüsü, influenza A ve B, kabakulak, suçiçeği-zoster virüsü, coxsackie virüsü, rotavirüs, ekhovirüs, mikoplazma pneumoniae ve bağışıklama (7). BOS(Beyin omurilik sıvısı) analizi genellikle normaldir, ancak bazı durumlarda oligoklonal gama-globulin bantları veya lenfositik inflamatuar reaksiyon (vakaların \% 25' inde hafif pleositoz bulunur) tespit edilebilir; yapılan mikrobiyolojik araştırmalar nadiren santral sinir sistemindeki viral enfeksiyonu tespit eder (8). Bizim hastamızda İnfluenza A enfeksiyonu ilişkili postenfeksiyöz serebellar ataksi ve konuşma bozukluğu gelişti, çekilen Beyin MRG ve Diffüzyon MRG normal saptand. LP (lumbal ponksiyon) yapılmadı. Sonbahar mevsiminde (Kasım ayı) bu enfeksiyonu geçiren hastamız, influenza aşısı yaptırmamıştı.

İnfluenza tedavisinde kullanılan antiviral ilaçlar Oseltamivir, Zanamivir, Amantadine ve Rimantadindir. Bununla birlikte, Oseltamivir yaygin olarak bulunan ve uygulaması kolay olanıdır. Hem tedavide hem de profilakside kullanılabilir. Oseltamivir genellikle çocuklarda iyi tolere edilmesine rağmen, bulantı, kusma, karın ağrısı, burun kanaması ve döküntü görülebilir (9). Nöroaminidaz inhibitörleri (oseltamivir, zanamivir) semptom başlangıcından sonraki ilk 48 saat içinde verildiğinde, influenza ilişkili kritik hastalığı olan çocuklarda mortalite azalmıştır (10). Bizim olgumuzda da semptomların başlangıcından sonraki ilk 48 saatte oseltamivir tedavisi başlanılmış ve belirgin klinik yanıt alınmıştır.

\section{SONUÇ}

Ataksinin nadir nedenlerinden birisi de Influenza enfeksiyonudur. Özellikle salgın mevsiminde ataksi ve konuşma bozukluğuyla gelen hipertransaminazemili hastalarda tanıda İnfluenza enfeksiyonu da düşünülmelidir.

Hasta Onamı: Tüm katılımcıların hakları korunmuş ve Helsinki Deklarasyonuna göre prosedürlerden önce yazılı bilgilendirilmiş onam alınmıştır.

Çıkar Çatışması: Yazarların beyan edecek çıkar çatışması yoktur.

Finansal Destek: Yazarlar bu çalışma için finansal destek almadıklarını beyan etmişlerdir. 


\section{KAYNAKLAR}

1. Wright P. Influenzaviruses. In: Kliegman RM, Behrman RE, Jenson HB, Stanton BF. Nelson Textbook of Pediatrics. 18th edition, Philadelphia, Saunders Elsevier; 2007; 1384-87.

2. Paules C, Subbarao K. Influenza. Lancet 2017; 390: 69708.

3. Silvennoinen $\mathrm{H}$, Peltola V, Lehtinen P. Clinical presentation of influenza in unselected children treated as outpatients. Pediatr Infect Dis J 2009; 28:372-75.

4. Kondrich J, Rosenthal M. Influenza in children. CurrOpin Pediatr. 2017 Jun; 29(3):297-02.

5. Papic N, Pangercic A, Vargovic M, Barsic B, Vince A, Kuzmand I. Liver involvement during influenza infection: perspective on the 2009 influenza pandemic. Influenza OtherRespirViruses. 2012; 6(3):2-5.
6. Caffarelli M, Kimia AA, Torres AR. Acute ataxia in children: a review of the differential diagnosis and evaluation in the emergency department. Pediatr Neurol. 2016; 65:14-30.

7. PedrosoJL, Vale TC, Braga-Neto P, Dutra LA, França MC Jr, Barsottini OGP. Acute cerebellar ataxia: differential diagnosis and clinical approach. Arq Neuropsiquiatr. 2019; 77(3):184-93.

8. Naselli A, Pala G, Cresta F, Finetti M, Biancheri R, Renna S. Acute post-infectious cerebellar ataxia due to co-infection of human herpesvirus- 6 and adenovirus mimicking myositi. Ital J Pediatr. 2014; 40: 98.

9. Kumar V. Influenza in Children.Indian J Pediatr 2017; 84(2):139-43.

10. Louie JK, Yang S, Samuel MC. Neuraminidase inhibitors for critically ill children with influenza. Pediatrics 2013; 132: 1539-45. 